\title{
Comparativo de indicadores econômicos da atividade leiteira de sistemas intensivos de produção de leite no Estado de Minas Gerais
}

\author{
Marcos Aurélio Lopes ${ }^{1}$, Glauber dos Santos ${ }^{2}$, Francisval de Melo Carvalho ${ }^{3}$
}

\begin{abstract}
RESUMO
A produção de leite do Brasil caminha para sistemas de produção com animais de maior produtividade. Entre esses sistemas, o de maior ocorrência é o confinamento total, seguido pelo semiconfinamento. Objetivou-se, com este trabalho, estimar e comparar alguns indicadores econômicos de fazendas leiteiras com alto volume de produção diária, em regimes de semiconfinamento e de confinamento total, localizadas no Estado de Minas Gerais. Foram utilizados os dados coletados entre março de 2008 e fevereiro de 2009, em seis sistemas de produção de leite, sendo três em semiconfinamento e três em confinamento total. Utilizou-se a metodologia do custo total e custo operacional, na análise de rentabilidade. Na análise econômica, por apresentarem resultados positivos, os sistemas de produção em semiconfinamento tiveram viabilidade econômica e condições de produzir no curto, médio e longo prazos, com consequente capitalização dos pecuaristas; enquanto os sistemas de produção em confinamento total apresentaram margem bruta negativa, isso indica que os produtores estão se descapitalizando e se endividando, pois as receitas auferidas não foram suficientes para pagar sequer as despesas operacionais efetivas.
\end{abstract}

Palavras-chave: análise de rentabilidade, bovinocultura de leite, custo de produção.

\section{ABSTRACT}

\section{Comparative economic indicators of milk production systems with high daily volume in Minas Gerais State}

Milk production in Brazil is heading toward production systems with livestock of increased productivity. The most frequent system is the total confinement, followed by the semi-confinement. The objective of this study was to estimate some economic indicators of dairy farms with high daily production volumes, under a semi-confinement and total confinement system, located in the state of Minas Gerais. The data used was collected between the months of March, 2008 and February, 2009, in six milk production systems, three being under semi-confinement and three under total confinement. The total and operational cost methodology was used for the production cost in the profitability analysis. In the economic analysis, for having shown positive results, the production systems in semi-confinement had economic viability and conditions of producing in the short, medium and long term, with consequent capitalization of farmers; while the total confinement production systems showed negative gross margin, which indicates that farmers are losing money and accumulating debt, because the revenues were not sufficient even to pay the effective operating expenses.

Key words: return analysis, dairy cattle, production cost.

\footnotetext{
Recebido para publicação em 22/03/2012 e aceito em 05/07/2012.

${ }^{1}$ Licenciado em Ciências Agrícolas, Doutor. Departamento de Medicina Veterinária, Universidade Federal de Lavras, Caixa Postal 3037, 37200-000, Lavras, Minas Gerais, Brasil. Bolsista do CNPq. malopes@dmv.ufla.br (autor correspondente).

${ }^{2}$ Zootecnista, Mestre. Departamento de Medicina Veterinária, Universidade Federal de Lavras, Caixa Postal 3037, 37200-000, Lavras, Minas Gerais, Brasil. Bolsista da CAPES. glauber_zoo@yahoo.com.br

${ }^{3}$ Engenheiro-Agrônomo, Doutor. Departamento de Administração e Economia, Universidade Federal de Lavras, Caixa Postal 3037, 37200-000, Lavras, Minas Gerais, Brasil. francarv@dae.ufla.br
} 


\section{INTRODUÇÃO}

A produção de leite do Brasil está caminhando de sistemas menos produtivos para sistemas de produção com animais de maior produtividade e, obviamente, envolvendo processos tecnológicos mais sofisticados (Stock et al., 2008). Entre esses sistemas mais produtivos, no Brasil, segundo o levantamento dos 100 maiores produtores de leite, o sistema de produção de maior ocorrência, com 50\%, foi o confinamento total, seguido do semiconfinamento, adotado por $33 \%$ dos produtores. Os restantes $17 \%$ dos sistemas eram baseados em pastagens (Milkpoint, 2010). Entretanto, é necessário conhecer a viabilidade econômica desses sistemas de produção, independentemente de qual seja o sistema adotado. Segundo Resende (2010), a lucratividade da produção leiteira está associada ao uso mais eficiente da mão de obra, ao uso de concentrado e à maior produtividade por vaca.

Para que a lucratividade se eleve, pode-se reduzir os custos ou aumentar as receitas. Considerando as condições de mercado, em razão das quais os produtores de leite não conseguem, no segmento agroindustrial, controlar o preço do produto que vendem, a estratégia para torná-lo competitivo ganha contornos claramente microeconômicos, envolvendo variáveis do ambiente interno da empresa rural, a exemplo dos indicadores de custos de produção (Lima, 2006). O aumento da eficiência produtiva torna-se fator decisivo para a competitividade do setor leiteiro (Reis et al., 2001).

Dados de custo de produção têm sido utilizados também para quantificar ineficiências econômicas (Tupy \& Yamaguchi, 2002), avaliar o efeito da escala de produção (Lopes et al., 2006), do tipo de sistema de criação (Lopes et al., 2007), do tipo de mão de obra (Lopes et al., 2004) e, ainda, do nível tecnológico (Lopes et al., 2009), bem como para comparar propriedades leiteiras (Carvalho et al., 2009). Porém, nenhum desses estudos apurou os custos de produção em propriedades com alto volume de produção diária.

Objetivou-se com este trabalho estimar e comparar alguns indicadores econômicos de fazendas leiteiras, localizadas no Estado de Minas Gerais, com alto volume de produção diária, em regime de semiconfinamento e de confinamento total.

\section{MATERIAL E MÉTODOS}

Foram utilizados os dados de seis sistemas de produção de leite, em fazendas das regiões central mineira e sul/ sudoeste de Minas. Os dados foram coletados entre os meses de março de 2008 e fevereiro de 2009. Os sistemas de produção foram divididos em dois grupos: semiconfinamento e confinamento total, sendo cada grupo constituído por três sistemas, o que correspondeu, para os dois grupos, à produção média diária de 19.867,04 e 17.982,30 $\mathrm{kg}$, respectivamente.

Os sistemas de produção em semiconfinamento foram caracterizados por apresentarem, na sua quase totalidade, matrizes mestiças Holandês-Gir, cujos grupos genéticos variaram entre $1 / 2,3 / 4,7 / 8$ ou $15 / 16$. A estimativa de produção de leite variou de 4.759,60 a $6.336,40 \mathrm{~kg} / \mathrm{vaca} /$ ano, o que corresponde a vacas em lactação com média de 13,04 a 17,36 kg de leite/dia, respectivamente. Todas as matrizes em lactação eram ordenhadas duas vezes ao dia. Já os sistemas de produção em confinamento total apresentavam vacas especializadas para produção de leite, sendo a maioria dos animais puros de origem (PO), pertencentes à raça Holandesa, com média de produção acima de $8.000 \mathrm{~kg} / \mathrm{vaca} / \mathrm{ano}$, durante todo o ano, correspondente a animais com produção diária de $22,25 \mathrm{~kg}$ de leite. Os animais receberam, no cocho, dieta completa e eram ordenhados três vezes ao dia.

Para melhor controle das despesas, em todos os sistemas de produção havia um almoxarifado para estocar os itens de consumo utilizados e um funcionário com dedicação exclusiva. Para dar saída aos insumos, era necessária uma requisição, indicando para qual centro de custo tal produto se destinaria. Após a autorização da saída do produto, era realizada a baixa, por meio de um software que controlava o estoque. Considerou-se o produto consumido, no momento da baixa no estoque.

Dentro de cada centro de custo, o responsável pelo lançamento escolhia para qual plano de contas determinada despesa iria. Esses planos de contas eram divididos em receitas e despesas. Como receitas, as opções eram de venda de leite, de animais ou de subprodutos e, para despesas, o concentrado proteico, concentrado energético, minerais/aditivos, forragem, salários, encargos sociais, EPI/uniforme, diarista, assistência técnica, mão de obra de terceiros, sanidade, insumos de reprodução, hormônios, BST, higiene de ordenha, manutenção periódica, impostos e taxas, energia elétrica, combustível e lubrificante, aluguel de máquinas, despesas administrativas, material para manejo de animais, manutenção de benfeitorias, frete, telefone e outros.

Para controlar e quantificar a mão de obra terceirizada, em função do tempo e do local de serviço prestado, foi desenvolvida em Excel uma planilha eletrônica. Foram apuradas todas as despesas e benefícios destinados aos funcionários permanentes, classificando-se as despesas em salários e encargos. Todos eram apropriados para os respectivos centros de custos, durante o mês de referência. No fim do mês, essas informações eram cadastradas no software de gerenciamento, para compor o custo de produção.

Para as despesas referentes a horas-máquinas (gastos com máquinas), foi desenvolvida uma planilha eletrô- 
nica em Excel, na qual se calculava a quantidade de horas trabalhadas pela máquina, bem como o local e a atividade realizada. Além de apurar o consumo de óleo diesel, também eram mensurados as demais despesas operacionais, como manutenções e honorários do tratorista, permitindo, assim, calcular o custo da hora-máquina. Não foram estimados neste custo a depreciação e o custo de oportunidade da máquina. Após estimados o custo operacional da hora-máquina e o tempo de serviço, cadastraram-se no software as despesas com horas-máquinas no centro de custo correspondente.

As despesas com os insumos destinados à alimentação dos animais foram levantadas em função da dieta formulada pelo nutricionista do sistema de produção, para cada categoria animal e pelo preço de compra de cada insumo. Depois disso, registrou-se a quantidade utilizada de cada insumo, separadamente. Com relação ao volumoso, todas as propriedades tinham o custo operacional efetivo desses alimentos e a quantidade de cada volumoso para cada categoria era fornecida pelo nutricionista.

O software utilizado para a análise de rentabilidade contemplou a metodologia do custo operacional, proposta por Matsunaga et al. (1976), e do custo total, de acordo com Lopes et al. (2007). Considerou-se como indicadores de rentabilidade a margem bruta (receita menos custo operacional efetivo), margem líquida (receita menos custo operacional total) e resultado (receita menos custo total). Além desses, estimou-se ainda a lucratividade 1, que foi calculada como sendo o resultado dividido pela receita total (Lucratividade $1(\%)=$ Resultado/Receita total); e a rentabilidade 1 , obtida pela divisão do resultado pelo total imobilizado, mais o custo operacional efetivo (Rentabilidade $1(\%)=$ Resultado/(Total imobilizado + Custo operacional efetivo)) (SEBRAE, 1998). Como lucratividade 2 , considerou-se a divisão da margem líquida pela receita total (Lucratividade $2(\%)=$ Margem líquida /Receita total); e, como rentabilidade 2, a divisão da margem líquida pelo total imobilizado, mais o custo operacional efetivo (Rentabilidade 2 $(\%)$ = Margem líquida/(Total imobilizado + Custo operacional efetivo)). Esses dois últimos indicadores foram estimados segundo Lopes et al. (2011).

Os índices produtivos e econômicos foram comparados por meio de análises estatísticas descritivas, utilizando-se o aplicativo MS Excel, e agrupados em tabelas, objetivando melhor comparação, discussão e apresentação dos resultados (Lopes et al., 2004).

\section{RESULTADOS E DISCUSSÃO}

O valor imobilizado em terras foi, em média, de $\mathrm{R} \$ 3.639 .133,33$ e R $\$ 2.541 .466,67$, representando 41,37 e $38,21 \%$ do total imobilizado nos sistemas de semiconfinamento e de confinamento total, respectivamente (Tabela
1). Esse maior valor apresentado pelos sistemas em semiconfinamento foi, em partes, devido ao maior preço da terra $(\mathrm{R} \$ 10.666,67$ versus $\mathrm{R} \$ 10.000,00 / \mathrm{ha})$ e pela maior extensão territorial desses sistemas.

O "patrimônio sem terra" foi 20,30\% maior nos sistemas em semiconfinamento, quando comparado com os de confinamento total, pela maior quantidade de animais existentes nos sistemas de semiconfinamento. Ao analisar cada item componente do patrimônio sem terra, percebese que as benfeitorias representaram $6,16 \%$ nos sistemas em semiconfinamento e $29,42 \%$ no confinamento total. Outra grande diferença foi observada no item animais, representando 88,93 e 60,61\% do patrimônio sem terra nos sistemas em semiconfinamento e em confinamento total. Os valores do custo de oportunidade do capital empatado nesses animais são considerados custos fixos; devese, portanto, atingir alta produtividade por animal para que possam ser "diluídos", refletindo-se em baixos percentuais no custo total.

Os indicadores "imobilizado por hectare" e "por matriz" podem ser utilizados como parâmetros na construção de um sistema de produção, na falta de um projeto de viabilidade econômica, desde que o sistema de referência tenha apresentado um resultado positivo. $\mathrm{O}$ indicador "imobilizado por kg de leite por dia" tem a mesma característica.

Ao analisar o total imobilizado por kg de leite produzido por dia, a diferença entre os sistemas foi baixa ( $\mathrm{R} \$ 253,87$ $=\mathrm{R} \$ 1.294,78-\mathrm{R} \$ 1.040,91$ ) (Tabela 1), sendo maior nos sistemas em semiconfinamento, por causa, principalmente, da menor produtividade por matriz e do alto valor imobilizado em animais. Ou seja, os sistemas em confinamento total não tiveram investimento tão mais alto do que os em semiconfinamento; o que aconteceu é que os itens de investimento são diferentes: um possui altos investimentos em terras e, o outro, é mais acentuado em instalações. $\mathrm{O}$ fator financeiro, no sentido de altos investimentos na produção, não deve ser o principal a ser considerado no momento de decidir por qual sistema de produção adotar. Devem ser consideradas outras questões, como a preferência do empresário, a rentabilidade dos sistemas, os conhecimentos agronômicos para produzir forragens de boa qualidade e a habilidade dos funcionários em lidar com os animais.

O valor imobilizado por hectare pode ser utilizado como indicador de intensificação dos sistemas de produção. Nos sistemas em semiconfinamento e confinamento total esses valores foram, respectivamente, em média, de R \$24.393,95 e R \$25.990,47. Segundo Gomes (2006), em um diagnóstico realizado no Estado de Minas Gerais, as propriedades que entregam mais de 1.000 litros de leite por dia tiveram o valor imobilizado/ha de $\mathrm{R} \$ 6.723,78$. Essa diferença pode ser consequência de fatores como o valor 
da terra entre as diferentes regiões; a quantidade de matrizes por hectare; o valor das matrizes e o maior uso de tecnologias.

Os valores do total imobilizado por matriz em lactação foram menores nos sistemas em semiconfinamento (Tabela 1), por apresentarem uma quantidade bem mais elevada de matrizes em lactação $(465,67)$ e menor preço médio por matriz R9\$3.833,33. Em contrapartida, os sistemas em confinamento total possuem, em média, 277,33 matrizes em lactação, avaliadas em $\mathrm{R} \$ 4.266,67$ cada uma, justificando seu maior capital imobilizado por matriz em lactação. Lopes et al. (2005) encontraram um valor médio imobilizado por matriz de $\mathrm{R} \$ 5.581,05$ e uma rentabilidade negativa $(3,12 \%)$, o que também aconteceu neste estudo, nos sistemas de confinamento. Duas situações podem estar acontecendo: baixa produtividade das matrizes ou alto investimento nos sistemas de produção.

$\mathrm{Na}$ composição da receita total, a venda de leite, de animais e de subprodutos representaram 42,52; 57,47 e $0,01 \%$, nos sistemas de produção em semiconfinamento, e 94,$67 ; 5,30$ e $0,03 \%$ nos sistemas em confinamento total (Tabela 2). A maior representatividade da venda de animais na receita total, nos sistemas de semiconfinamento, contribuiu para que a rentabilidade média fosse $9,10 \%$, enquanto, nos de confinamento total ela foi negativa $(-1,78 \%)$. A maior representação da venda de animais no semiconfinamento deveu-se a vários fatores: 1) adoção da venda estratégica de animais (leilões, feiras e exposições), por um dos sistemas de produção, conseguindo assim bons preços para os animais comercializados; 2) alto valor da venda de animais e 3) menor produtividade das matrizes em lactação, o que representa menor venda com leite.
Essa contribuição na receita tende a ser maior nos sistemas de produção com as seguintes características: pequeno produtor, cujos animais não são especializados para produção de leite; teoricamente, animais de dupla aptidão; produtores que passam por uma crise financeira e, em momento de alta no preço da arroba de carne, vendem os animais para o corte; produtores que têm rebanho com boa genética e comercializam melhor os animais, que foi o caso dos sistemas de produção em semiconfinamento. Lopes et al. (2007) encontraram 11,66\% da receita total com a venda de animais, valor superior ao encontrado nos sistemas em confinamento total, possivelmente pelas diferenças de produção (288,86 versus $6.227,15 \mathrm{~kg} /$ dia), mostrando que a venda de animais tende a ser mais representativa em sistemas com menor comercialização diária de leite, exceto para sistemas de produção que adotam a venda estratégica de animais.

Segundo Nascif (2008), em períodos de preço baixo de leite, a maioria dos sistemas que utilizam cruzamentos com gado zebu tem a venda de animais com uma forma de complementar a renda da atividade, o que não acontece com raças mais especializadas. Moraes et al. (2004), em um estudo econômico da produção de leite com gado mestiço F1 holandês-zebu, encontraram uma lucratividade média de $28,9 \%$, sendo a venda de bezerros desmamados responsável por $25 \%$ da receita total. Segundo outros pesquisadores (Almeida Jr et al., 2002; Marques et al., 2002; Lopes et al., 2009) a receita com a venda de animais variou de 28,08 a 4,16\%. Esses valores mostram que ocorre grande variação nos percentuais da composição da receita. O que vai definir a maior ou menor ênfase na venda de animais são as metas do sistema de produção, a necessidade de levantar receitas (Lopes et al., 2009), bem como

Tabela 1. Comparativo das médias dos recursos disponíveis na atividade leiteira nos sistemas de produção em semiconfinamento e confinamento total, no Estado de Minas Gerais, durante o período de março de 2008 a fevereiro de 2009

\begin{tabular}{|c|c|c|c|c|}
\hline \multirow{2}{*}{ Especificação } & \multicolumn{2}{|c|}{ Semiconfinamento } & \multicolumn{2}{|c|}{ Confinamento total } \\
\hline & Média & $\%$ & Média & $\%$ \\
\hline Valor do patrimônio em terra $(\mathbf{R} \$)$ & 3.639.133,33 & 41,37 & $2.541 .466,67$ & 38,21 \\
\hline Valor do patrimônio sem terra (R\$) & $5.157 .412,76$ & 58,63 & 4.110.436,54 & 61,79 \\
\hline Valor em benfeitorias $(\mathrm{R} \$)$ & $317.676,67$ & 6,16 & $1.209 .091,32$ & 29,42 \\
\hline Valor em máquinas $(\mathrm{R} \$)$ & $174.171,20$ & 3,38 & $316.205,82$ & 7,69 \\
\hline Valor em equip./implementos (R\$) & $78.898,23$ & 1,53 & $93.806,07$ & 2,28 \\
\hline Valor em animais $(\mathrm{R} \$)$ & $4.586 .666,67$ & 88,93 & $2.491 .333,33$ & 60,61 \\
\hline Área (ha) & 354,51 & & 243,93 & \\
\hline Quantidade média de matrizes (Cab.) & $1.367,33$ & & 639,00 & \\
\hline Quantidade de mão de obra (homem/dia) & 12,67 & & 14,33 & \\
\hline Média diária de leite produzido (kg/dia) & $6.622,35$ & & $6.227,15$ & \\
\hline Total imobilizado $(\mathbf{R} \$)$ & $8.796 .546,10$ & & $6.651 .903,21$ & \\
\hline Total imobilizado por ha $(\mathrm{R} \$)$ & $24.393,95$ & & $25.990,47$ & \\
\hline Total imobilizado por matriz em lactação (R\$) & $15.902,28$ & & $19.358,28$ & \\
\hline Total imobilizado por animal $(\mathrm{R} \$)$ & $7.375,84$ & & $10.403,77$ & \\
\hline Total imobilizado por $\mathrm{kg}$ de leite produzido por dia $(\mathrm{R} \$)$ & $1.294,78$ & & $1.040,91$ & \\
\hline
\end{tabular}


os aspectos referentes à saúde do rebanho (Demeu et al, 2011).

A participação da venda dos subprodutos foi muito baixa nos dois sistemas de produção. Embora muitos pecuaristas não considerem o esterco como fonte de receita, segundo Lopes et al. (2004) esse subproduto pode ser uma alternativa de renda e representar até $1,51 \%$ da receita total, ou reduzir o uso de fertilizantes químicos, quando aplicado em áreas de agricultura.

Ao se compararem os indicadores de eficiência econômica margem bruta (receita total - custo operacional efetivo), margem líquida (receita total - custo operacional total) e resultado (receita total - custo total), observa-se que tais resultados foram positivos nos sistemas em semiconfinamento (Tabela 2), evidenciando que a atividade tem condições de sobreviver no curto, médio e longo prazos. No confinamento total, esses indicadores foram negativos. Resultados de pesquisas têm mostrado que a atividade leiteira apresenta resultado positivo
(Mancio et al., 1999; Moraes et al., 2004; Gomes \& Filho 2007; Oliveira et al., 2007; Silva et al., 2008); outros, que a atividade apresenta margem líquida positiva (Gomes, 2006; Lopes et al., 2007; Nascif, 2008); a maioria tem mostrado apenas a margem bruta positiva (Reis, 2001; Fassio et al., 2006; Lopes et al., 2007; Prado et al., 2007).

A lucratividade e a rentabilidade foram calculadas por duas metodologias diferentes, na intenção de aumentar a possibilidade de compará-las com outros estudos, uma vez que não raramente ocorre a comparação de índices levantados de maneiras diferentes. A lucratividade 2 (Margem líquida x 100/receita total) foi, em média, de 22,65 e $4,29 \%$, nos sistemas em semiconfinamento e confinamento total, respectivamente. Já a rentabilidade 2 (Margem líquida x 100/Capital total imobilizado + custo operacional efetivo), índice utilizado para comparar atividades diferentes, nos sistemas em semiconfinamento e confinamento total, foram de 10,44 e-1,03, respectivamente, ou seja, os sistemas em confinamento total tiveram uma rentabilida-

Tabela 2. Comparativo das médias do resumo das análises de rentabilidade da atividade leiteira dos sistemas de produção semiconfinamento e confinamento total, no Estado de Minas Gerais, durante o período de março de 2008 a fevereiro de 2009, em R\$

\begin{tabular}{|c|c|c|c|c|}
\hline \multirow{2}{*}{$\frac{\text { Sistema de produção }}{\text { Especificação }}$} & \multicolumn{2}{|c|}{ Semiconfinamento } & \multicolumn{2}{|c|}{ Confinamento total } \\
\hline & Média & DP & Média & DP \\
\hline Receita & 4.410.143,09 & 5.843.615,17 & $1.926 .617,86$ & $906.155,54$ \\
\hline Leite & $1.875 .097,03$ & $1.642 .896,22$ & $1.823 .873,71$ & $979.564,14$ \\
\hline Animais & 2.534.397,38 & 4.217.214,69 & $102.095,48$ & $72.667,23$ \\
\hline Subprodutos & 648,68 & $1.123,55$ & 0,00 & 0,00 \\
\hline Custo operacional total (COT) & 2.112.293,42 & $1.915 .459,99$ & 2.086.428,99 & 1.135.120,39 \\
\hline Custo operacional efetivo (COE) & $2.088 .375,46$ & $1.899 .441,26$ & $2.036 .405,72$ & $1.095 .494,14$ \\
\hline Depreciaçãa & 23.917,96 & $17.850,57$ & $\mathbf{5 0 . 0 2 3 , 2 7}$ & $39.735,52$ \\
\hline Depreciação da infraestrutura & $23.917,96$ & $17.850,57$ & $50.023,27$ & $39.735,52$ \\
\hline Depreciação de matrizes & 0,00 & 0,00 & 0,00 & 0,00 \\
\hline Custo total $(\mathbf{C T})$ & $2.268 .645,60$ & 2.076.192,34 & 2.144.445,79 & $1.133 .745,26$ \\
\hline Custo fixo (CF) & 178.411,42 & $176.076,70$ & 105.387,32 & 38.116,33 \\
\hline Remuneração da terra & $112.206,84$ & $118.105,01$ & $28.119,60$ & $14.309,40$ \\
\hline Remuneração do capital investido & $38.924,40$ & $38.736,17$ & $24.806,19$ & $9.213,73$ \\
\hline Remuneração do empresário & 0,00 & 0,00 & 0,00 & 0,00 \\
\hline Impostos fixos (IPVA + ITR) & $3.362,22$ & $3.968,05$ & $2.438,27$ & $1.081,50$ \\
\hline Depreciação & 23.917,96 & $\mathbf{1 7 . 8 5 0 , 5 7}$ & $50.023,27$ & $39.735,52$ \\
\hline Depreciação da infraestrutura & $23.917,96$ & $17.850,57$ & $50.023,27$ & $39.735,52$ \\
\hline Depreciação de matrizes & 0,00 & 0,00 & 0,00 & 0,00 \\
\hline Custo variável (CV) & $2.090 .234,18$ & $1.900 .353,89$ & 2.039.058,47 & $1.097 .748,85$ \\
\hline Custo operacional efetivo (s/impostos) & $2.085 .013,24$ & $1.895 .605,29$ & $2.033 .967,45$ & $1.095 .010,12$ \\
\hline Remuneração do capital de giro & $5.220,94$ & $4.748,60$ & $5.091,01$ & $2.738,74$ \\
\hline Margem bruta & $2.321 .767,63$ & $3.953 .854,30$ & $-109.787,85$ & $202.384,96$ \\
\hline Margem líquida & $2.297 .849,67$ & $3.938 .954,18$ & $-159.811,12$ & $241.074,73$ \\
\hline Resultado (lucro ou prejuízo) & $2.141 .497,49$ & $3.777 .438,89$ & $-217.827,93$ & $242.943,68$ \\
\hline Lucratividade $1(\%)$ & 17,50 & 35,83 & $-8,14$ & 10,60 \\
\hline Rentabilidade $1(\%)$ & 9,10 & 17,11 & $-1,78$ & 2,16 \\
\hline Lucratividade $2(\%)$ & 22,65 & 34,20 & $-4,29$ & 13,02 \\
\hline Rentabilidade $2(\%)$ & 10,44 & 17,26 & $-1,03$ & 2,56 \\
\hline Quantidade de leite ( $\mathrm{kg} / \mathrm{ano})$ & $2.417 .156,53$ & $1.972 .037,74$ & $2.260 .568,28$ & $1.127 .439,76$ \\
\hline Quantidade em equivalente leite (kg/ano) & $5.575 .546,11$ & $7.178 .913,45$ & 2.394.994,05 & $1.022 .244,49$ \\
\hline
\end{tabular}

1 - Fórmula considerando o resultado da atividade; 2 - Fórmula considerando a margem líquida da atividade. DP $=$ Desvio padrão

Rev. Ceres, Viçosa, v. 59, n.4, p. 458-465, jul/ago, 2012 
de negativa, bem menor, por exemplo, do que a poupança (6\% a.a.).

Como indicador da eficiência reprodutiva, pode-se observar a percentagem de vacas em lactação, em relação ao total de animais, que foi em média de $36,91 \%$, nos sistemas em semiconfinamento, e de $44,74 \%$, no confinamento total (Tabela 3). Essa maior percentagem pode ser atribuída ao maior uso da técnica de transferência de embrião; ter ocorrido maior taxa de descarte e, ainda, ser devida à maior quantidade de funcionários em um dos sistemas de produção em confinamento total; funcionários esses que eram destinados a uma mais intensa observação de cio.

A produtividade média de leite por vaca em lactação foi de 15,62 e $22,25 \mathrm{~kg} / \mathrm{vaca} / \mathrm{dia}$, nos sistemas em semiconfinamento e confinamento total, respectivamente (Tabela 3). Parte da diferença pode ser atribuída a fatores genéticos (mestiço holandês-zebu x holandês PO) e parte devida ao gasto de energia dos animais em pastejo. Segundo Bargo et al. (2002), vaca em lactação, recebendo dieta completa, produziram $25,19 \%$ (38,1 versus $28,5 \mathrm{~kg}$ / dia) mais leite do que vacas pastando e suplementadas com concentrado. Kolver et al. (2000) e White et al. (2002) encontraram aumentos da ordem de 34,07 e 11\%, com dietas completas, em comparação com os obtidos em sistema de pastagem mais concentrado. A diferença na produção de leite dá-se, principalmente, por não se atender aos requerimentos de energia, no pastejo, uma vez que a ingestão de matéria seca é menor (Bargo et al., 2002) e os animais gastam mais energia pastejando (Agnew et al., 2000), além da menor eficiência energética apresentada pelos animais no pastejo, em virtude da maior produção de metano, em comparação com a dos animais que recebem dieta com alto concentrado (Lana \& Russuell, 2001).

A produção de leite por hectare foi maior nos sistemas em confinamento total $(9.317,88 \mathrm{~kg} / \mathrm{ha} / \mathrm{ano})$, por ter apresentado maior média de produção por animal e taxa de lotação, em comparação com a dos sistemas em semiconfinamento $(6.818,31 \mathrm{~kg} / \mathrm{ha} / \mathrm{ano})$.

Por ponto de equilíbrio, entende-se o nível de produção em que uma atividade tem seus custos totais iguais às suas receitas totais (Lopes \& Carvalho, 2000). Ele foi de $1.509,29 \mathrm{~kg}$ de leite/dia nos sistemas em semiconfinamento e não foi atingido em nenhum dos sistemas de produção em confinamento total, pelo fato de apresentarem um custo variável unitário superior ao preço de ven-

Tabela 3. Comparativo de alguns índices técnicos/gerenciais e econômicos da atividade leiteira nos sistemas de produção em semiconfinamento e confinamento total, no Estado de Minas Gerais, durante o período de março de 2008 a fevereiro de 2009

\begin{tabular}{|c|c|c|c|c|}
\hline \multirow{2}{*}{$\begin{array}{l}\text { Sistemas de produção } \\
\text { Índices técnicos/gerenciais e econômicos }\end{array}$} & \multicolumn{2}{|c|}{ Semiconfinamento } & \multicolumn{2}{|c|}{ Confinamento total } \\
\hline & Média & DP & Média & DP \\
\hline Vacas lactação/total de animais (\%) & 36,91 & 4,08 & 44,74 & 5,14 \\
\hline Taxa de lotação (UA/ha) & 3,2 & 0,65 & 2,49 & 0,52 \\
\hline Vaca lactação/área para produção de leite (UA/ha) & 1,27 & 0,24 & 1,12 & 0,11 \\
\hline Produção de leite/ vaca em lactação (kg/dia) & 15,62 & 2,28 & 22,25 & 3,87 \\
\hline Produção de leite/ total de vacas (kg/dia) & 4,84 & 1,66 & 9,75 & 4,68 \\
\hline Produção de leite/área (kg/ha/ano) & $6.818,31$ & $1.756,51$ & $9.317,88$ & 884,99 \\
\hline Produção em equivalente leite/área (kg/ha/ano) & $11.994,72$ & $6.223,26$ & $9.356,13$ & $1.019,14$ \\
\hline Produção de leite dia/mão de obra (kg/serviço) & 522,67 & 172,88 & 434,55 & 230,53 \\
\hline Relação vaca lactação/homem & 31,78 & 15,82 & 20,78 & 13,23 \\
\hline Ponto de equilíbrio diário (kg de leite) & $1.509,29$ & $1.067,44$ & $*$ & $*$ \\
\hline Ponto de equilíbrio anual (kg de leite) & $550.892,62$ & $389.616,07$ & $*$ & $*$ \\
\hline Remuneração do capital s/ terra (\% a.a.) & 18,41 & 34,89 & $-10,78$ & 6,96 \\
\hline Remuneração do capital c/ terra (\% a.a.) & 26,9 & 54,23 & $-17,53$ & 11,29 \\
\hline Custo operacional efetivo/preço de leite (\%) & 109,85 & 6,17 & 116,49 & 9,45 \\
\hline Custo operacional total/preço de leite (\%) & 112,26 & 5,87 & 121,97 & 11,42 \\
\hline Custo total/preço de leite $(\%)$ & 120,08 & 7,9 & 124,4 & 11,64 \\
\hline Gasto com concentrado/preço do leite (\%) & 42,45 & 3,34 & 47,72 & 4,33 \\
\hline Margem bruta anual por vaca em lactação (R \$/vaca lactação) & $2.517,27$ & $3.919,38$ & $-932,55$ & 639,9 \\
\hline Margem líquida anual por vaca em lactação (R \$/vaca lactação) & $2.413,62$ & $3.950,62$ & $-1.294,40$ & 734,7 \\
\hline Resultado por vaca em lactação (R \$/vaca lactação) & $2.085,17$ & $3.927,08$ & $-1.454,85$ & 736,59 \\
\hline Depreciação/COT (\%) & 2,21 & 0,58 & 4,42 & 1,31 \\
\hline COE/COT $(\%)$ & 97,84 & 0,55 & 95,58 & 1,31 \\
\hline Custo fixo/custo total (\%) & 8,38 & 1,04 & 6,19 & 1,27 \\
\hline Custo variável/custo total (\%) & 91,62 & 1,04 & 93,81 & 1,27 \\
\hline Depreciação/custo total (\%) & 2,02 & 0,54 & 4,34 & 1,29 \\
\hline
\end{tabular}

DP=Desvio padrão * Não foi possível calcular pelo fato do custo variável ter sido maior do que o preço unitário de venda do leite. 
da do leite. Isso mostra que são necessários esforços gerenciais para se aumentar a produtividade das matrizes, sem, contudo, aumentar o custo variável, pois, assim, o custo variável unitário iria diminuir, ou ainda, para se conseguir maior preço pelo leite entregue aos laticínios.

Quando se compara a remuneração do capital, os sistemas semiconfinamento conseguiram remunerar tanto o capital sem e com terra, em 18,41 e 20,90\%, respectivamente. Em contrapartida, essas remunerações não foram alcançadas nos sistema de confinamento total. Entretanto o desvio padrão foi elevado, mostrando que algum sistema conseguiu remunerar o capital, evidenciando que os sistemas em semiconfinamento foram mais rentáveis.

O custo operacional efetivo, o custo operacional total e o custo total foram superiores ao preço do leite no semiconfinamento e confinamento total (Tabela 3). No entanto, no semiconfinamento, a rentabilidade foi positiva, o que não ocorreu no confinamento total. Isso foi possível por causa da grande contribuição da venda de animais na receita total. Essa constatação ressalta a maior dependência de altos preços do leite em sistemas mais tecnologicamente intensificados, já que os custos são elevados.

A utilização de concentrados na dieta das matrizes teve maior representatividade no preço unitário do leite, nos sistemas de confinamento total $(47,72 \%)$, enquanto no semiconfinamento, esse valor foi um pouco menor $(42,45 \%)$. Considerando-se que o preço unitário do leite no confinamento foi um pouco maior $(7,44 \%)$, constatase que, se esse preço fosse idêntico nos dois sistemas, a percentagem do uso de concentrado no confinamento total seria maior, ou seja, o preço do leite subestima a representação do concentrado. Entretanto, em sistema de pastejo com alto nível tecnológico, a inclusão de concentrado é quase semelhante a um confinamento total. Segundo Mertens (1987), deve-se manejar bem as pastagens para baixar a quantidade de fibra, para que se possa, assim, diminuir a inclusão de concentrado na dieta.

A depreciação representou 2,21 e 4,42\% do custo operacional total nos sistemas em semiconfinamento e no confinamento total (Tabela 3). A diferença pode ser atribuída ao maior valor imobilizado por vaca em lactação nos sistemas em confinamento total. Isso exige que esse tipo de sistema seja composto por animais de alta produção, para diluir o custo com a depreciação. A relação depreciação/COT fornece uma informação da eficiência de utilização dos recursos disponíveis para produção de leite, quando comparados sistemas semelhantes, e mostra uma ideia da infraestrutura necessária para produção de leite, quando comparados sistemas diferentes.

O custo fixo é composto pela depreciação, impostos fixos e custo de oportunidade da terra, do capital investido e do empresário (quando houver). A relação entre cus- to fixo e custo total foi 8,38 e $6,19 \%$, no semiconfinamento e no confinamento total. $\mathrm{O}$ custo fixo teve uma maior representatividade no sistema de semiconfinamento, pela grande contribuição da remuneração da terra. Ou seja, em sistemas de produção em semiconfinamento, em que a terra seja muito valorizada, o custo fixo pode representar mais do que em sistemas de confinamento total. Um dos componentes do custo fixo é a depreciação. Em sistemas de confinamento total, essa é maior do que nos sistemas de semiconfinamento. Entretanto, quando se analisou o custo fixo como um todo, esse foi maior no semiconfinamento. Essa ressalva é válida porque muitos acreditam que esse item do custo de produção é mais elevado em sistemas de confinamento total.

\section{CONCLUSÕES}

$\mathrm{Na}$ análise econômica, por apresentarem resultado positivo, os sistemas de produção em semiconfinamento mostraram viabilidade econômica e condições de produzir no curto, médio e longo prazos, com consequente capitalização dos pecuaristas; enquanto os sistemas de produção em confinamento total apresentaram margem bruta negativa, o que indica que os produtores estão se descapitalizando e se endividando, pois as receitas auferidas não foram suficientes para pagar sequer as despesas operacionais efetivas.

\section{AGRADECIMENTOS}

Os autores agradecem a FAPEMIG pelo apoio financeiro na realização deste trabalho.

\section{REFERÊNCIAS}

Agnew RE \& Yan T (2000) Impact of recent research on energy feeding systems for dairy cattle. Livestok Production Science, 66:197-215

Almeida Júnior GA, Lopes MA \& Pinatto F (2002) Efeito da venda de animais na rentabilidade de um sistema intensivo de produção de leite tipo B no estado de São Paulo. In: Reunião anual da sociedade brasileira de Zootecnia, Recife. Anais, Universidade Federal de Pernambuco. p.34-35.

Bargo F, Muller LD, Delahoy JE \& Cassidy TW (2002) Performance of high producing dairy cows with three different feeding systems combining pasture and total mixed rations. Journal of Dairy Science, 85:2948-2963.

Carvalho FM, Ramos OE \& Lopes MA (2009) Análise comparativa dos custos de produção de duas propriedades leiteiras no município de Unai - MG, no período de 2003 e 2004. Ciência e Agrotecnologia, 33:1705-1711.

Demeu FA, Lopes MA, Costa GM, Rocha CMBM, Santos G \& Franco Neto A (2011) Influência do descarte involuntário de matrizes no impacto econômico da mastite em rebanhos leiteiros. Ciência e Agrotecnologia, 35:195-202.

Fassio LH, Reis RP \& Geraldo LG (2006) Desempenho técnico e econômico da atividade leiteira em Minas Gerais. Ciência e Agrotecnologia, 30:1154-1161. 
Gomes AL \& Filho JBSF (2007) Economias de escala na produção de leite: uma análise dos Estados de Rondônia, Tocantins e Rio de Janeiro. Revista de Economia e Sociologia Rural, 45:591619

Kolver ES, Muller LD, Varga GA \& Cassidy TJ (2000) Synchronization of ruminal degradation of supplemental carbohydrate with pasture nitrogen in lactating dairy cows. Journal of Dairy Science, 81:2017-2028.

Lana RP \& Russell JB (2001) Efeitos da monensina sobre a fermentação e sensibilidade de bactérias ruminais de bovinos sob dietas ricas em volumoso ou concentrado. Revista Brasileira de Zootecnia, 30:254-260.

Lima ALR (2006) Eficiência produtiva e econômica da atividade leiteira em Minas Gerais. Dissertação de Mestrado. Universidade Federal de Lavras, Lavras. 77p.

Lopes MA \& Carvalho FM (2000) Custo de produção do leite. Lavras, Universidade Federal de Lavras. 42p. (Boletim Agropecuário, 32).

Lopes MA, Cardoso MG, Carvalho FM, Lima ALR, Dias AS \& Carmo EA (2007) Efeito do tipo de sistema de criação nos resultados econômicos de sistemas de produção de leite na região de lavras (MG) nos anos 2004 e 2005. Ciência Animal Brasileira, 8:359-371.

Lopes MA, Dias AS, Carvalho FM, Lima ALR, Cardoso MG \& Carmo EA (2009) Resultados econômicos de sistemas de produção de leite com diferentes níveis tecnológicos na região de Lavras, MG nos anos 2004 e 2005. Ciência e Agrotecnologia, $33: 252-260$.

Lopes MA, Lima ALR, Carvalho FM, Reis RP, Santos IC \& Saraiva FH (2005) Efeito da escala de produção nos resultados econômicos de sistemas de produção de leite na região de Lavras (MG): um estudo multicasos. Boletim de Indústria Animal, 63:177-188.

Lopes MA, Lima ALR, Carvalho FM, Reis RP, Santos IS \& Saraiva FH (2004) Controle gerencial e estudo da rentabilidade de sistemas de produção de leite na região de Lavras (MG). Ciência e Agrotecnologia, 28:883-892.

Lopes MA, Lima ALR, Carvalho FM, Reis RP, Santos IC \& Saraiva FH (2006) Efeito da escala de produção nos resultados econômicos de sistemas de produção de leite na região de Lavras (MG): um estudo multicasos. Boletim da Indústria Animal, 63:177-188.

Lopes MA, Resende MC, Carvalho FM, Carmo EA, Cardoso MG, Santos G \& Lima ALR (2011) Estudo da rentabilidade de sistemas de produção de leite na região de Nazareno (MG). Ciência Animal Brasileira, 12:58-69.

Mancio AB, Schiffler EA \& Londoño Hernández FI (1999) Eficiência técnica e econômica de quatro empresas de produção de leite da região de São Carlos, SP. Arquivo Brasileiro de Medicina Veterinária e Zootecnia, 51:283-286.

Marques VM, Reis RP, Sáfadi T \& Reis AJ (2002) Custos e escala na pecuária leiteira: estudo de casos em Minas Gerais. Ciência e Agrotecnologia, 26:1027-1034.
Matsunaga M, Bemelmans PF, Toledo PEN, Dulley RD, Okawa H \& Pedroso IA (1976) Metodologia de custo de produção utilizado pelo IEA. Agricultura em São Paulo, 23:123-139.

Mertens DR (1987) Predicting intake and digestibility using mathematical methods of ruminal function. Journal Animal Science, 64:1548-1558.

Milkpoint (2010) Os 100 maiores produtores de leite do Brasil: levantamento top 100. Disponível em: <http:// www.milkpoint.com.br>. Acessado em: 12 de janeiro de 2011.

Moraes ACA, Coelho SG, Ruas JRM, Ribeiro JCVC, Vieira FAP \& Menezes AC (2004) Estudo técnico e econômico de um sistema de produção de leite com gado mestiço F1 Holandês-Zebu. Arquivo Brasileiro de Medicina Veterinária e Zootecnia, 56:745749 .

Nascif C (2008) Indicadores técnicos e econômicos em sistemas de produção de produção de leite de quatro mesorregiões do estado de Minas Gerais. Dissertação de mestrado. Universidade Federal de Viçosa, Viçosa. 110p.

Oliveira AS, Cunha DNFV, Campos JMS, Vale SMLR \& Assis AJ (2007) Identificação e quantificação de indicadores-referência de sistemas de produção de leite. Revista Brasileira de Zootecnia, 36:507-516.

Prado E, Geraldo LG \& Cardoso BM (2007) Rentabilidade da exploração leiteira em uma propriedade durante cinco anos. Arquivo Brasileiro de Medicina Veterinária e Zootecnia, 59:501507.

Reis RP, Medeiros AL \& Monteiro LA (2001) Custo de produção da atividade leiteira na região sul de Minas Gerais. Organizações Rurais e Agroindustriais, 3:45-54.

Resende JC (2010) Determinantes de lucratividade em fazendas leiteiras em Minas Gerais. Tese de doutorado. Universidade Federal de Lavras, Lavras. 145p.

Gomes ST (2006) Diagnóstico da pecuária leiteira do Estado de Minas Gerais em 2005: relatório de pesquisa. Belo Horizonte, FAEMG. 156p.

Serviço Brasileiro de Apoio às Micros e Pequenas Empresas SEBRAE (1998) Curso de capacitação rural. Goiás, SEBRAE. $34 \mathrm{p}$.

Silva HA, Moraes HSKA, Guimarães VA \& Carvalho EHPCF (2008) Análise da viabilidade econômica da produção de leite a pasto e com suplementos na região dos Campos Gerais - Paraná. Ciência Rural, 38:445-450.

Stock LA, Carneiro AV, Carvalho GR, Zoccal R, Martins PC \& Yamaguchi LCT (2008) Sistemas de produção e sua representatividade na produção de leite no Brasil. In: Reunião da Associação Latino-americana de Produção Animal, Cuzco. Anais, ALPA. p.17-18

Tupy O \& Yamaguchi LCT (2002) Identificando benchmarks na produção de leite. Revista de Economia e Sociologia Rural, 40:81-96.

White SL, Benson GA, Washburn SP \& Green JT (2002) Milk production and economic measures in confinement or pasture systems using seasonally calved holstein and jersey cows. Journal of Dairy Science, 85:95-104. 